\title{
Long-term safety of budesonide/formoterol for the treatment of elderly patients with bronchial asthma
}

\author{
KATSUNORI KAGOHASHI ${ }^{1}$, HIROAKI SATOH ${ }^{1}$, GEN OHARA $^{1}$, KUNIHIKO MIYAZAKI $^{2}$, \\ MIO KAWAGUCHI $^{2}$, KOICHI KURISHIMA ${ }^{2}$ and NOBUYUKI HIZAWA ${ }^{2}$ \\ ${ }^{1}$ Division of Respiratory Medicine, Mito Medical Center, University of Tsukuba, Mito, Ibaraki 310-0015; \\ ${ }^{2}$ Division of Respiratory Medicine, Faculty of Medicine, University of Tsukuba, Tsukuba, Ibaraki 305-8575, Japan
}

Received September 10, 2013; Accepted January 24, 2014

DOI: 10.3892/etm.2014.1515

\begin{abstract}
The long-term safety of budesonide/formoterol (BUD/FM) inhalation has not been fully evaluated, particularly in elderly patients with bronchial asthma. To evaluate the 12-month safety of BUD/FM inhalation for elderly asthmatic patients, the changes in serum potassium levels and pulse rate were examined. A retrospective chart review was conducted of consecutive patients who were treated with BUD/FM inhalation (two inhalations of 160/4.5 mg, twice daily; Symbicort Turbuhaler, AstraZeneca) at a hospital between February 2010 and January 2012. A total of 350 patients were treated with BUD/FM inhalation during the study period and were followed up over 12 months. The mean age of the patients was 60 years, and $19.4 \%$ and $21.4 \%$ of the patients were aged $65-74$ years and $\geq 75$ years, respectively. One hundred and fourteen (32.6\%) of the 350 patients continued the inhalation therapy for $>12$ months. Compared with the pretreatment data, reductions in serum potassium levels at 1, 6 and 12 months were not observed, even in the patients aged $65-74$ and $\geq 75$ years. There was also no increase in the pulse rate at 1,6 and 12 months, even in the patients aged $65-74$ and $\geq 75$ years. The usual dosage of BUD/FM showed no adverse effects on the serum potassium levels and pulse rate in the adults, including the elderly with persistent asthma.
\end{abstract}

\section{Introduction}

The use of an inhaled corticosteroid (ICS) and long-acting 32-agonist (LABA) combination inhaler is recommended by the Global Initiative for Asthma and most other asthma treatment guidelines as the first choice to control chronic asthma for patients in whom control with ICS monotherapy is

Correspondence to: Professor Hiroaki Satoh, Division of Respiratory Medicine, Mito Medical Center, University of Tsukuba, Miya-machi 3-2-7, Mito, Ibaraki 310-0015, Japan

E-mail: hirosato@md.tsukuba.ac.jp

Key words: bronchial asthma, budesonide/formoterol, inhalation, elderly, pulse rate, serum potassium difficult (1-4). Budesonide/formoterol (BUD/FM) inhalation aerosol is an ICS and LABA combination, which is administered twice daily via one hydrofluoroalkane-pressurized metered-dose inhaler and has been approved for use in many countries for the long-term maintenance treatment of persistent asthma (2-4). With regard to safety, while the short-term safety in ICS (5-7) and ICS/LABA (8-10) has been evaluated, the long-term safety has yet to be fully investigated $(11,12)$, particularly in elderly patients with bronchial asthma. In the present retrospective study, an evaluation of the 1-, 6- and 12-month safety of BUD/FM inhalation for elderly asthmatic patients was performed, and the changes in serum potassium levels and pulse rate were observed.

\section{Patients and methods}

Patients. Clinicopathological data for all the patients with bronchial asthma were obtained by retrospective review from the database at the University of Tsukuba, Mito Medical Center, Mito Kyodo General Hospital (Mito, Japan). The consecutive patients who were diagnosed with bronchial asthma and treated with BUD/FM inhalation aerosol (two inhalations of 160/4.5 mg, twice daily; Symbicort Turbuhaler; AstraZeneca, Osaka, Japan) between February 2010 and January 2012 at the hospital, were entered in this study.

In order to evaluate the 1-year safety of BUD/FM inhalation, a medical chart review of the patients up to January 2013 was performed. Demographic data, including age, gender and comorbid diseases were retrieved from the patient medical records. This retrospective study conformed to the Ethical Guidelines for Clinical Studies issued by the Ministry of Health, Labor and Welfare of Japan.

Study population. The patient population was divided into three age groups: The $<65$ years group, the $65-74$ years group and the $\geq 75$ years group. The demographic data and safety of BUD/FM inhalation therapy were compared among the three age groups. Adverse effects were counted as they occurred during the study period. Blood samples were obtained from the patients in order to measure the serum potassium levels, and pulse rates were measured at pretreatment and 1, 6 and 12 months following the initiation of the BUD/FM inhalation therapy. 
Statistical analysis. The serum potassium levels and pulse rate prior to treatment and at 1,6 and 12 months after treatment were compared using Wilcoxon rank sum test. To compare the different groups of patients, the chi-square test was also used. All statistical analysis were performed using SPSS software, version 10.1 for Windows (SPSS Inc., Chicago, IL, USA) and $\mathrm{P}<0.05$ was considered to indicate a statistically significant difference.

\section{Results}

Patient characteristics. Table I shows patient characteristics. A total of 350 patients with bronchial asthma were treated with BUD/FM inhalation during the study period. There were 189 males and the median age was 60 years (range: $17-93$ years). In total, 207 (59.2\%) patients were aged <65 years, 68 (19.4\%) patients were 65-74 years old and $75(21.4 \%)$ patients were $\geq 75$ years old (Table I). Among the 350 patients, 160 (45.7\%) patients had comorbid diseases, including cardiovascular diseases in 74 patients (54 patients had hypertension, 12 had chronic heart failure, six had arrhythmia and five had ischemic heart disease). Fifty-six patients (74.7\%) aged $\geq 75$ years had one or more comorbid diseases, and $64.7 \%$ and $24.1 \%$ of patients aged 65-74 years and $<65$ years had one or more comorbid diseases, respectively. There was a significant difference in the incidence of one or more comorbid diseases between patients aged $\geq 65$ years and those aged $<65$ years $(\mathrm{P}=0.001$; chi-square test). However, there was no difference in the incidence of comorbid diseases between patients aged $\geq 65-74$ years and those aged $<75$ years $(\mathrm{P}=0.603$; chi-square test).

Treatment of bronchial asthma. An effective control of bronchial asthma was obtained, so BUD/FM inhalation therapy in $141(40.3 \%)$ of the 350 patients was terminated or changed to ICS inhalation within 3 months. Similarly, in 95 (27.1\%) patients, the inhalation therapy was terminated within 3-12 months. Therefore, the inhalation therapy was continued for $>12$ months in 114 (32.6\%) patients.

\section{Safety of BUD/FM inhalation}

Adverse events. Four (1.1\%) patients exhibited hoarseness, and three of them were aged $\geq 75$ years. Two $(0.6 \%)$ patients developed a tremor and both were $<75$ years of age. Two $(0.6 \%)$ patients had oral candidiasis and arrhythmia, and each of them was $\geq 75$ years of age. All adverse events were transient and disappeared shortly after the termination of the inhalation therapy.

Serum potassium. Fig. 1 shows the changes in serum potassium levels between pretreatment and 1 month after the initiation of BUD/FM therapy. There was no statistical difference between them $(\mathrm{P}=0.567)$. As shown in Table II, serum potassium levels at 6 and 12 months were not different from the levels before treatment $(\mathrm{P}=0.941$ and $\mathrm{P}=0.822$, respectively). In the 65-74 years group and the $\geq 75$ years group, serum potassium levels at 1, 6 and 12 months was not different from the levels before treatment. The changes in serum potassium levels in patients with cardiovascular diseases, and those $\geq 75$ years with comorbid diseases were also examined. There was no statistical differences between serum potassium levels at these intervals (Table II).
Table I. Characteristics of 350 patients with bronchial asthma.

\begin{tabular}{|c|c|}
\hline Variable & Data \\
\hline Age (years) & $60(17-93)^{\mathrm{a}}$ \\
\hline$\leq 65$ & $207(59.2 \%)$ \\
\hline $65-74$ & $68(19.4 \%)$ \\
\hline$\geq 75$ & $75(21.4 \%)$ \\
\hline \multicolumn{2}{|l|}{ Gender } \\
\hline Male & 189 \\
\hline Female & 161 \\
\hline \multicolumn{2}{|l|}{ Comorbid diseases } \\
\hline Present & $160(45.7 \%)$ \\
\hline Cardiovascular diseases & 74 \\
\hline Hypertension & 54 \\
\hline Chronic heart failure & 12 \\
\hline Arrhythmia & 6 \\
\hline Ischemic heart disease & 5 \\
\hline Others & 4 \\
\hline Respiratory diseases & 43 \\
\hline COPD & 26 \\
\hline Pneumonia & 5 \\
\hline Others & 8 \\
\hline Metabolic diseases & 43 \\
\hline Diabetes & 29 \\
\hline Thyroid disease & 5 \\
\hline Others & 9 \\
\hline Renal and urologic diseases & 14 \\
\hline Autoimmune diseases & 9 \\
\hline Psychiatric diseases & 8 \\
\hline Malignant diseases & 7 \\
\hline Other diseases & 14 \\
\hline \multicolumn{2}{|l|}{ Other controllers } \\
\hline Leukotriene antagonists & 41 \\
\hline Xanthines & 19 \\
\hline Oral steroids & 2 \\
\hline
\end{tabular}

COPD, chronic obstructive pulmonary disease. ${ }^{\text {amedian }}$ with range in parentheses.

Pulse rate. Fig. 2 shows changes in pulse rate between pretreatment and 1 month after the initiation of BUD/FM therapy. The pulse rate 1 month after the initiation of BUD/FM therapy was significantly lower than the pulse rate prior to treatment $(\mathrm{P}=0.001)$. In the $\geq 75$ years group, the pulse rate was also decreased at the 6-month interval $(\mathrm{P}=0.046)$; these results may be due to the achievement of control of bronchial asthma. However, there was no statistically significant difference in pulse rate between any other age groups or intervals (Table III). The change in pulse rate in asthmatic patients with cardiovascular diseases and those $\geq 75$ years with comorbid diseases were also examined, and no statistical differences between any age groups and any intervals were identified (Table III). 
Table II. Change in serum potassium levels prior to and following BUD/FM inhalation.

\begin{tabular}{|c|c|c|c|}
\hline Patients & $\begin{array}{l}\text { Pretreatment K level } \\
\text { (median, range; mEq/l) }\end{array}$ & $\begin{array}{l}\text { Post-treatment K level } \\
\text { (median, range; mEq/l) }\end{array}$ & P-value \\
\hline \multicolumn{4}{|l|}{ All patients } \\
\hline 1-month interval & $4.1,3.4-5.4$ & $4.2,3.1-5.3$ & 0.567 \\
\hline 6-month interval & $4.1,3.4-5.0$ & $4.1,3.5-5.1$ & 0.941 \\
\hline 12-month interval & $4.2,3.4-5.4$ & $4.2,3.5-5.2$ & 0.822 \\
\hline \multicolumn{4}{|c|}{ Patients aged $\geq 65$ years } \\
\hline 1-month interval & $4.2,3.5-5.4$ & $4.2,3.6-4.9$ & 0.286 \\
\hline 6-month interval & $4.2,3.5-5.0$ & $4.1,3.6-5.1$ & 0.457 \\
\hline 12-month interval & $4.2,3.4-5.4$ & $4.3,3.5-5.2$ & 0.989 \\
\hline \multicolumn{4}{|c|}{ Patients aged $\geq 75$ years } \\
\hline 1-month interval & $4.2,3.6-5.4$ & $4.2,3.6-4.9$ & 0.691 \\
\hline 6-month interval & $4.1,3.6-5.0$ & $4.1,3.6-4.8$ & 0.909 \\
\hline 12-month interval & $4.1,3.4-5.4$ & $4.3,3.5-5.0$ & 0.472 \\
\hline \multicolumn{4}{|c|}{ Patients with cardiovascular diseases } \\
\hline 1-month interval & $4.1,3.4-4.9$ & $4.3,3.2-5.0$ & 0.680 \\
\hline 6-month interval & $4.1,3.5-5.0$ & $4.3,3.6-5.1$ & 0.345 \\
\hline 12-month interval & $4.1,3.0-5.0$ & $4.2,3.6-5.0$ & 0.731 \\
\hline \multicolumn{4}{|c|}{ Patients $\geq 65$ years with cardiovascular diseases } \\
\hline 1-month interval & $4.2,3.7-4.9$ & $4.3,3.5-4.9$ & 0.967 \\
\hline 6-month interval & $4.3,3.7-5.0$ & $4.1,3.6-5.1$ & 0.795 \\
\hline 12-month interval & $4.3,3.7-5.0$ & $4.3,3.7-5.0$ & 0.948 \\
\hline
\end{tabular}

BUD/FM, budesonide/formoterol; K, potassium.

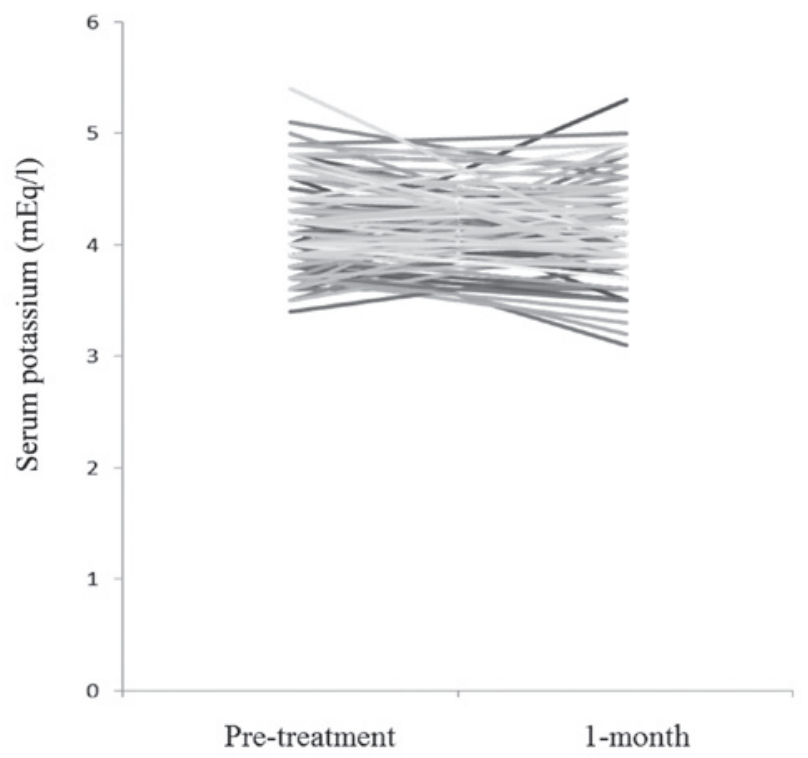

Figure 1. Serum potassium levels prior to and 1 month after the initiation of BUD/FM inhalation. No statistically significant difference was identified $(\mathrm{P}=0.567)$. BUD/FM, budesonide/formoterol.

\section{Discussion}

BUD, a potent and safe ICS with a high affinity for glucocorticoid receptors, is approved in many countries for the treatment of asthma (2-4). The addition of inhaled LABA provides a more effective means of improving lung function and asthma control than increasing the dose of ICS in patients whose asthma is not adequately controlled. FM is unique amongst LABAs as it has a fast onset of action and a long duration of effect (2,3). BUD and FM, as individual components and in combination, possess well-defined efficacy as well as pharmacological and safety profiles when administered through a single metered-dose inhaler (4,8-10). In the present study, an evaluation of safety over 12 months of the usual dose of BUD/FM was performed, and the serum potassium levels and pulse rate were examined in elderly patients with bronchial asthma.

There has been increasing interest in the treatment of elderly patients with bronchial asthma (13). However, clinical information regarding asthmatic patients aged $\geq 75$ years has been scarcely available as such patients are not usually included in clinical trials and retrospective care analysis. Therefore, there is scientific uncertainty regarding the risks and benefits of treatment with ICS/LABA in asthmatic patients aged $\geq 75$ years. To assess the short-term efficacy and safety of the treatment in the elderly, we previously reviewed our clinical data from consecutive patients with bronchial asthma treated with BUD/FM (14). Even with the existence of comorbid diseases in the elderly, BUD/FM was effective with no high incidences of adverse events, such as hoarseness, tremor, arrhythmia and oral candidiasis (14). The incidences observed were similar to those reported in previous studies in young adults and middle-aged patients (8-10). 
Table III. Change in pulse rates prior to and following BUD/FM inhalation.

\begin{tabular}{|c|c|c|c|}
\hline Patients & $\begin{array}{l}\text { Pretreatment pulse rare } \\
\text { (median, range; bpm) }\end{array}$ & $\begin{array}{l}\text { Post-treatment pulse rate } \\
\text { (median, range; bpm) }\end{array}$ & P-value \\
\hline \multicolumn{4}{|l|}{ All patients } \\
\hline 1-month interval & $80,48-132$ & $77,46-110$ & 0.001 \\
\hline 6-month interval & $81,48-120$ & $80,52-120$ & 0.081 \\
\hline 12-month interval & $80,48-120$ & $77,50-109$ & 0.050 \\
\hline \multicolumn{4}{|c|}{ Patients aged $\geq 65$ years } \\
\hline 1-month interval & $78,54-110$ & $77,56-110$ & 0.210 \\
\hline 6-month interval & $81,54-106$ & $76,56-105$ & 0.163 \\
\hline 12-month interval & $80,54-106$ & $76,56-109$ & 0.288 \\
\hline \multicolumn{4}{|c|}{ Patients aged $\geq 75$ years } \\
\hline 1-month interval & $81,60-110$ & $78,58-110$ & 0.093 \\
\hline 6-month interval & $81,60-106$ & $76,56-105$ & 0.046 \\
\hline 12-month interval & $81,60-106$ & $77,56-109$ & 0.128 \\
\hline \multicolumn{4}{|c|}{ Patients with cardiovascular diseases } \\
\hline 1-month interval & $80,52-120$ & $79,46-110$ & 0.140 \\
\hline 6-month interval & $80,54-120$ & $80,56-120$ & 0.915 \\
\hline 12-month interval & $78,60-120$ & $77,60-92$ & 0.762 \\
\hline \multicolumn{4}{|c|}{ Patients aged $\geq 65$ years with cardiovascular diseases } \\
\hline 1-month interval & $81,54-102$ & $80,56-97$ & 0.325 \\
\hline 6-month interval & $81,54-102$ & $80,56-98$ & 0.726 \\
\hline 12-month interval & $80,54-102$ & $76,58-92$ & 0.807 \\
\hline
\end{tabular}

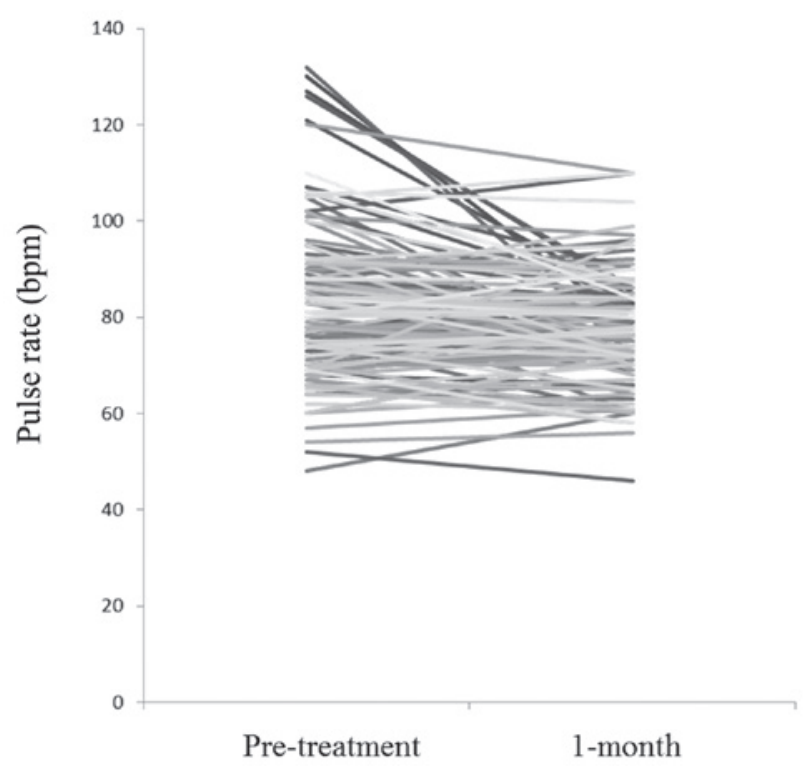

Figure 2. Pulse rate prior to and 1 month after the initiation of BUD/FM inhalation. The pulse rate 1 month after the BUD/FM inhalation was significantly lower than that after treatment $(\mathrm{P}=0.001)$. BUD/FM, budesonide/formoterol

Previous studies have investigated the 1-year safety of the usual dosage of FM (5-7) and BUD/FM inhalation for asthma patients (8-10). In these studies, the mean age of the patients evaluated was $\sim 30-40$ years (8-10). Rosenhall et al evaluated the 1-year safety of BUD/FM (8), and Maspero et al examined mometasone furoate/FM (9), and they concluded that both treat- ments were safe and well tolerated in patients with persistent asthma $(8,9)$. However, in these studies, there was no investigation into the changes in serum potassium levels and pulse rate. With regard to the evaluation of these parameters, Hinkle et al studied heart rate in pediatric subjects with stable asthma (15), and Malolepszy et al examined serum potassium levels and heart rate in high-dose FM in patients with acute bronchial obstruction (16). Recently, Saito and Hasunuma studied the short-term safety of high dose BUD/FM in asthmatic patients, whose mean age was 44.3 years (11). In their study, $>10 \%$ of patients showed palpitation, tachycardia and decreased serum potassium levels in a 2.5-fold higher dose of BUD/FM than the usual dose of therapy (11). In the present study, the median age of the patients was 60 years, and $40.8 \%$ and $21.4 \%$ of them were $\geq 65$ and $\geq 75$ years of age, respectively. Aging is associated with a high prevalence of comorbid diseases (13). Elderly patients are predisposed to comorbid diseases, such as diabetes, cardiovascular and cerebrovascular diseases. In the present study, the $\geq 65$ years group had a higher proportion of patients with comorbid diseases than those $<65$ years of age. However, there were neither significant reductions in serum potassium levels nor changes in pulse rate in the three age groups, including those with comorbid diseases.

The results of the present study revealed novel findings; however, there were a number of limitations in this study. This was a small-sized retrospective study in a single institution. Serum potassium levels and pulse rate were not evaluated in every patient and a quality of life analysis was not performed in this study. Therefore, we consider that conclusive outcomes were not derived from this study. However, the methodology 
used, which was based on an audit of the information from clinical practice documented in the patient records, may provide some clinical information that was not available from clinical trials. Additionally, reporting the treatment experiences in patients with bronchial asthma, including those of elderly patients with some comorbid diseases, may be of clinical significance.

In conclusion, the usual dosage of BUD/FM (two inhalations of 160/4.5 mg, twice daily) showed no adverse effects on the serum potassium levels and pulse rate in Japanese adults, including the elderly with persistent asthma.

\section{References}

1. Global Initiative for Asthma (GINA): Global Strategy for Asthma Management and Prevention. NHLBI/WHO Workshop Report National Heart, Lung, and Blood Institute, National Institutes of Health, 2010.

2. Edwards SJ, von Maltzahn R, Naya IP and Harrison T: Budesonide/formoterol for maintenance and reliever therapy of asthma: a meta analysis of randomised controlled trials. Int J Clin Pract 64: 619-627, 2010.

3. Korenblat PE and Rosenwasser LJ: Budesonide/formoterol pressurized metered-dose inhaler for patients with persistent asthma Allergy Asthma Proc 31: 190-202, 2010.

4. McCormack PL and Lyseng-Williamson KA: Budesonide/formoterol: a review of its use as maintenance and reliever inhalation therapy in asthma. Drugs 67: 2407-2431, 2007.

5. Donohue JF, Hanania NA, Fogarty C, Campbell SC, Rinehart M and Denis-Mize K: Long-term safety of nebulized formoterol: results of a twelve-month open-label clinical trial. Ther Adv Respir Dis 2: 199-208, 2008.

6. Randell J, Saarinen A, Walamies M, Vahteristo M, Silvasti M and Lähelmä S: Safety of formoterol after cumulative dosing via Easyhaler and Aerolizer. Respir Med 99: 1485-1493, 2005.
7. Hamilos DL, D'Urzo A, Levy RJ, et al: Long-term safety study of levalbuterol administered via metered-dose inhaler in patients with asthma. Ann Allergy Asthma Immunol 99: 540-548, 2007.

8. Rosenhall L, Elvstrand A, Tilling B, et al: One-year safety and efficacy of budesonide/formoterol in a single inhaler (Symbicort Turbuhaler) for the treatment of asthma. Respir Med 97: 702-708, 2003.

9. Maspero JF, Nolte H and Chérrez-Ojeda I; P04139 Study Group: Long-term safety of mometasone furoate/formoterol combination for treatment of patients with persistent asthma. J Asthma 47: 1106-1115, 2010.

10. Peters SP, Prenner BM, Mezzanotte WS, Martin P and O'Brien CD: Long-term safety and asthma control with budesonide/formoterol versus budesonide pressurized metered-dose inhaler in asthma patients. Allergy Asthma Proc 29: 499-516, 2008.

11. Saito $T$ and Hasunuma T: Safety and tolerability of high-dose budesonide/formoterol via Turbuhaler ${ }^{\circledR}$ in Japanese patients with asthma: a randomized, double-blind, crossover, active comparator-controlled, phase III study. Clin Drug Investig 32: 51-61, 2012.

12. Noonan M, Leflein J, Corren J and Staudinger H: Long-term safety of mometasone furoate administered via a dry powder inhaler in children: Results of an open-label study comparing mometasone furoate with beclomethasone dipropionate in children with persistent asthma. BMC Pediatr 9: 43, 2009.

13. Reed CE: Asthma in the elderly: diagnosis and management. J Allergy Clin Immunol 126: 681-687, 2010.

14. Kagohashi K, Kurishima K, Satoh H, et al: Safety and efficacy of budesonide/formoterol in a single inhaler (Symbicort Turbuhaler) for the treatment of asthma. J New Remedies and Clinics 59: 2087-2092, 2010 (In Japanese).

15. Hinkle J, Hinson J, Kerwin E, et al: A cumulative dose, safety and tolerability study of arformoterol in pediatric subjects with stable asthma. Pediatr Pulmonol 46: 761-769, 2011.

16. Malolepszy J, Böszörményi Nagy G, Selroos O, Larsso P and Brander R: Safety of formoterol Turbuhaler at cumulative dose of 90 microg in patients with acute bronchial obstruction. Eur Respir J 18: 928-934, 2001. 